\title{
Tetzapotitlan-Teayo. Precisiones toponímicas en la Huaxteca meridional, México
}

\section{Tetzapotitlan-Teayo. Toponymic Accuracies in the Southern Huaxteca, Mexico}

\author{
Emmanuel Márquez Lorenzo \\ (D) ORCID: 0000-0003-2161-7803 \\ Centro Universitario del Norte-Universidad de Guadalajara, México \\ emmanuel.marquez@cunorte.udg.mx
}

\section{Resumen:}

Este trabajo tiene como objetivo discernir el significado del término Teayo, el cual no corresponde a «tortuga de piedra», como tradicionalmente ha sido aceptado a partir del estudio de Los Lienzos de Tuxpan. La presentación de evidencias de origen arqueológico, etnohistórico, lingüístico y etnográfico permite desarrollar la propuesta de que la denominación «Teayo» para la región tetzapoteca ocurrió por razones ideológicas, relacionadas con el intenso culto a las diosas de la fertilidad Teem y Chicomecóatl en la época prehispánica.

Palabras clave: Castillo de Teayo, Tetzapotitlan, Teem, Chicomecóatl, escultura prehispánica

\section{Abstract:}

This paper aims at discerning the meaning of the word Teayo, which does not mean «stone turtle» as has been traditionally accepted following the study of cloth maps known as Los Lienzos de Tuxpan. The presentation of evidence of archeological, ethno-historical, linguistic and ethnographic origin makes it possible to propose that the application of the name Teayo to the Tetzapotec region occurred for ideological reasons related to the fervent worship in pre-Hispanic times of Teem and Chicomecóatl, two fertility goddesses.

Key words: Teayo Castle, Tetzapotitlan, Teem, Chicomecóatl, pre-Hispanic sculptures 


\title{
Introducción
}

\begin{abstract}
n 1872, un grupo de nativos de Tihuatlán se acercó a los terrenos de la lo-
- calidad de Teayo, ubicada en la Huaxteca meridional, en México, con el fin de aprovechar sus tierras y establecer un asentamiento en sus alrededores. Esta nueva población realizó el hallazgo de diversos basamentos piramidales tras la quema de grandes zonas de pastizales, los cuales aprovecharon para la elaboración de sus viviendas. Entre los basamentos resaltó uno, al que percibieron como un "castillo», referente que fue integrado a la denominación de esta área (Márquez, 2014: 63; 2015c: 147). De este modo, el poblado se adjudicó el nombre de Castillo de Teayo con la finalidad de establecer distancia territorial con una «cercana Hacienda de Teayo» (Easby, 1962: 139). No obstante, Seler -fuente primaria para el estudio de este sitio de naturaleza prehispánica- no hace referencias a ninguna hacienda, sino a la quema de un área boscosa donde se estableció la nueva población (Seler, 1908: 414). Es aquí donde inician los primeros cuestionamientos, los cuales ayudarán a comprender, en mayor medida, las dinámicas de esta población en la época prehispánica.
\end{abstract}

\section{Breve historia prehispánica de Castillo de Teayo}

La localidad de Castillo de Teayo (Tetzapotitlan), se encuentra ubicada en el norte del estado de Veracruz, México, en la región Huaxteca, sobre los $20^{\circ} 45^{\prime}$ latitud y los $97^{\circ} 38^{\prime}$ longitud. Sus elevaciones son menores a los $100 \mathrm{msnm}$ y colinda con el municipio de Temapache hacia el norte, con el de Tihuatlán al este y con el estado de Puebla por su parte sur y oeste. Su territorio pertenece, cabe decir, a elevaciones del Eje Neovolcánico, entre la Sierra Madre Oriental y el Golfo de México (Instituto Nacional de Estadística y Geografía, 2020).

De acuerdo con los materiales cerámicos de la localidad reportados por distintos investigadores, puede determinarse que los primeros pobladores del sitio prehispánico de Tetzapotitlan se asentaron hacia el Clásico Tardío o Epiclásico (600-900 d.C). Aquí, Stresser-Péan documenta cerámica típicamente huaxteca, coincidente con materiales de los periodos V y VI (Stresser-Péan, 2008: 135). Por su parte, Orellana (1948) y Marquina (1951) son más específicos y mencionan los tipos negro y rojo sobre blanco, barro rojizo, negro fino y polícroma que se asemejan a la de la zona central de Veracruz (Orellana, 1948: 
4-5; Marquina, 1951: 459). Por el contrario, los reportes de García (1944, 1950, $1959,1965,1976 a$ y 1976b) no son tan confiables, pues en su obra se infiere cierta manipulación de la información con tendencia a realzar la presencia tolteca en la localidad (Márquez, 2012b:49). Por su parte, Easby (1962), Solís (1981, 1986, 1996), Maclaren (2002), Robles (2007), Umberger (2007) y Márquez (2009, 2012a, 2012b, 2014, 2015a, 2015b, 2015c, 2017, 2019, 2020) han presentado evidencia suficiente acerca de la presencia mexica en la localidad, principalmente durante la segunda mitad del siglo XV.

A la par de los hallazgos de basamentos piramidales realizados en Castillo de Teayo, gran cantidad de esculturas arqueológicas quedaron al descubierto por aquellos colonos que se acercaron a este territorio hacia 1872. Este corpus, de especial curiosidad para los nuevos habitantes, fue acercado a dos áreas principales: el basamento piramidal que aún permanece en el centro del poblado, y un altar cristiano ubicado en su momento a mitad del camino en la salida a Ixhuatlán de Madero en el actual Barrio de la Cruz (Márquez, 2015a:392, 418).

Con base en el estudio de una de las esculturas encontradas por Seler en Castillo de Teayo, catalogada como monumento 4, se ha demostrado que el topónimo original del sitio pertenece a la voz nahua Tetzapotitlan, «lugar de mameyes» (Márquez, 2012a:97-135; 2014:63; 2015a; 2017:9-22; 2019). En su momento, este descubrimiento fue determinante para dar inicio a la depuración estricta de información contenida en fuentes escritas y documentación pictográfica en relación con el sitio. Dicha postura fue asumida para ubicar otras localidades aledañas mencionadas en fuentes, cuya identificación ha sido basada más en la especulación que en la propia información arqueológica. ${ }^{1}$

En el monumento 4 de Castillo de Teayo se aprecia una de las variantes toponímicas del lugar, y quizá la principal por provenir del análisis del dato arqueológico mismo y no de una fuente colonial. Aquí, la repetición del glifo tetzapotl «mamey» (véase Figura 1) tiene referencia explícita como locativo, de acuerdo con la propia lógica del monumento (Márquez, 2012a:115). En dicha escultura, además, se expresa el inicio de una de las tantas guerras ejecutadas contra esta provincia

\footnotetext{
${ }^{1}$ La postura con la cual se asumen los argumentos de este y otros de mis trabajos, es apelando a la evidencia material por sobre la ideológica, es decir, es el contraste con la naturaleza cosificada lo que permite determinar la certeza de las hipótesis y la formulación de teorías, procedimiento de contraste que pocas veces es atendido por los propios investigadores. De este modo, debemos «adecuar nuestros prejuicios teóricos a los restos de los hechos y no al revés» (Márquez, 2012b:96).
} 
de población tének² por parte de la Triple Alianza, la cual inició en 1479 y culminó en 1480, según se registra entre los mismos glifos del monumento. Además, la importancia de la pieza radica en su carácter conmemorativo en relación con un hecho bélico, un hallazgo inusitado en relación con lo que se ha documentado en otras regiones conquistadas por los mexicas y sus aliados.

Figura 1. Detalle del topónimo Tetzapotitlan en el monumento 4 de Castillo de Teayo

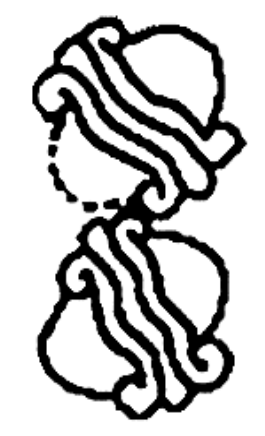

Fuente: Márquez (2012a:111)

A su vez, es necesario señalar que ocurrieron ataques constantes en contra de Tetzapotitlan y otras provincias de la Huaxteca meridional por parte del Altiplano, desde por lo menos 1444, cuando Nezahualcóyotl realizó la primera sujeción del área. El orden mantenido por este gobernante se vulneró a partir de 1458, tras su declinación a favor del de México Tenochtitlan, una vez conformada la Triple Alianza. Esta situación ocasionó la inconformidad de las poblaciones tének, quienes ahora debían dirigir su tributo a un grupo extranjero en el poder (Márquez, 2012b:20-48). Por su parte, en fuentes escritas suele explicarse este primer levantamiento de grupos tének a partir del asesinato de pochtecas (comerciantes) (Durán, 1975:216), debido al conocimiento de sus actividades de espionaje. Eran utilizados para recopilar información de provincias no sujetas, «con el fin de conocer diversidad de aspectos como la ubicación geográfica, organización social, recursos económicos, entre otros. De esta forma, los gobernantes planeaban estrategias de invasión a partir de los datos obtenidos» (Márquez, 2015b:161).

Ahora bien, acerca de la matanza de pochtecas en la Huaxteca meridional, las fuentes escritas mencionan también la preparación de las poblaciones tének

\footnotetext{
2 Se dará preferencia al uso del término tének por ser la autodenominación de estos pueblos. Debe recordarse que la acepción cuexteca, o huaxteca, alude a la forma colonial mexica de referencia, la cual es enteramente despectiva y no debiera seguir utilizándose en los estudios actuales (Urquijo, 2008:11).
} 
para la guerra, erigiendo "cinco cercas» de piedra para retener a las huestes que serían enviadas por la Triple Alianza (Durán, 1975:216; De Alva, 1984:109-110).

Respecto de esta construcción, se ha documentado evidencia arqueológica en los terrenos de la Mesa de Metlaltoyuca, donde alcanza los 2 y 3 metros de altura (Graulich y Ochoa, 2003:105). Además, existe representación de esta barda en una de las láminas del Códice Xicotepec (Stresser-Péan, 2008).

No obstante, de acuerdo con fuentes documentales, una de las intervenciones en contra de Tetzapotitlan fue la ocurrida en 1476 (Márquez, 2017:26), inferida a partir del Códice en Cruz, en donde se aprecia a un guerrero de nombre "cóatl» asociado con el topónimo de la localidad (Códice en Cruz, en Mohar, 2009). Sin embargo, el dominio de la Triple Alianza sobre la población tetzapoteca en diversas épocas siempre fue breve, lo cual explica por qué se documentan nuevos movimientos bélicos contra esta provincia entre 1479 y 1480, y de manera definitiva, entre 1486 y 1487 (Márquez, 2017:26-35). El desplazamiento territorial, las ejecuciones de nativos y la colonización tuvieron grandes consecuencias culturales que, de acuerdo con los datos existentes, revelan una modificación extrema de la ideología religiosa en sus manifestaciones fenoménicas; además de un desplazamiento de la lengua original, tének, hacia una oficial, impuesta implícitamente por los grupos dominantes: el náhuatl (Márquez, 2017:97-106; 2020). ${ }^{3}$

Cabe mencionar que una parte considerable de los monumentos encontrados en Tetzapotitlan apoya estos planteamientos, al menos 27 de las de 60 esculturas de la localidad muestran algún tipo de filiación con la cultura mexica (Márquez, 2015a:38, 42, 129-130, 153-154,159, 229-248; 2020). Esto es contrario a lo que se esperaría de una provincia de suma importancia para la Huaxteca, donde las representaciones escultóricas también dan cuenta de númenes propios de su formación cultural, tales como Mam, Teem o Dhipak, dioses del rayo, la tierra y el maíz; respectivamente. Por su parte, la documentación pictográfica discursiva oficial de los grupos del Altiplano permite sostener la identificación del sitio como Tetzapotitlan (Márquez, 2012a:97-135; 2014:63; 2015a; 2017:9-22; 2019). Es decir, independientemente del topónimo tének propio de su lengua nativa (el cual, además se desconoce), hay evidencia de una referencia locati-

\footnotetext{
${ }^{3}$ En diversas investigaciones sobre Tetzapotitlan se ha determinado la existencia de una extracción poblacional de fuerzas bélicas tének de la localidad, para ser sacrificadas en la inauguración de una nueva etapa constructiva del Templo Mayor de México Tenochtitlan en 1487. Posteriormente, se enviaron familias completas y varones a Tetzapotitlan quienes emparentaron con mujeres nativas, iniciando una nueva formación cultural, en la cual las manifestaciones ideológicas promovidas corresponden en su mayor parte a las mexicas, como se observa en los discursos oficiales evidenciados en la escultura del sitio (Márquez, 2017:104, 140-141; 2015a:123, 156-162).
} 
va por un grupo dominante que conquistó y sujetó la zona, carácter que se ve reforzado en documentos pictográficos producidos en la región, como son Los Lienzos de Tuxpan, donde las variaciones glíficas del topónimo de Tetzapotitlan -o Tetzapolco- tampoco dejan lugar a dudas (véase Figura 2).

Figura 2. Toponimia de Tetzapotitlan -o Tetzapolco- en Los Lienzos de Tuxpan

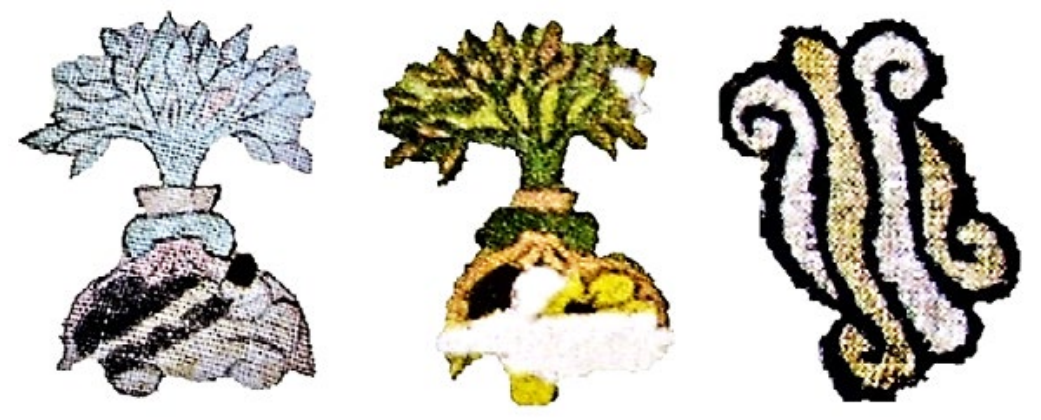

Fuente: Márquez (2012b:16)

De acuerdo con las investigaciones más recientes, Tetzapotitlan mantuvo una presencia mexica constante después de 1480, durante la cual se llevó a cabo el dominio político y territorial del sitio, además del religioso que se intensificó hacia 1487 tras un fenómeno de colonización territorial (Márquez, 2012a; 2012b; 2014; 2015a; 2015b; 2015c; 2017).

El Códice Mendoza ayuda a comprender parte de la relación de avasallamiento contra la localidad de Tetzapotitlan, debido a que documenta la instauración de gobernantes provenientes del Altiplano, entre los cuales se encuentran los denominados Tlacatecuhtli y Tlacochcálcatl (Códice Mendoza, en Galindo y Villa, 1979:18). Dichas autoridades tenían la función de administrar los recursos tributados por los pueblos sometidos, siendo colocados dentro de los más importantes espacios de las sociedades sujetas (Márquez, 2015b:171). De hecho, el Manuscrito 040 Historia Mexicana 1194-1221 (Hernández, 2009) explicita la construcción de un templo en honor de Huitzilopochtli, dentro de Tzicoac, en la región «mazateca», es decir, entre los tének (recordemos que estas poblaciones se autodenominan «el pueblo del venado») (Manuscrito 040, en Hernández, 2009; Márquez, 2017:28-29).

Dentro del Códice Mendoza, se señala también a un personaje llamado Ome Cuauhtli, de rango militar Tezcacoacatl, instaurado en la provincia de Xoconochco (Soconusco) para mayor sujeción del sitio, es decir, con la intención de evitar rebeliones (Códice Mendoza, en Galindo y Villa, 1979:18). La presencia de estas figuras de poder tanto político como militar, puede estar demostrada, a su vez, 
en representaciones escultóricas de sujetos provistos con vestidura de serpiente, identificados como figuras Cihuacóatl para el Altiplano (Matos, 2015:87). ${ }^{4}$ En la Huaxteca meridional tales personajes están documentados para Metlaltoyuca y Tetzapotitlan, y son evidencia arqueológica de la división de cargos propia de la Triple Alianza, que hacía uso de una contraparte en sus gobiernos (cogobiernos) (Márquez, 2021). Esta inferencia permite comprender, a su vez, la imposición de verdaderos sistemas políticos propios del Altiplano en provincias ocupadas territorialmente (véase Figura 3).

Figura 3. Representación de gobernante de rango militar Tezcacoacatl y Cihuacóatl en el Códice Mendoza y en esculturas procedentes de Metlaltoyuca y Tetzapotitlan
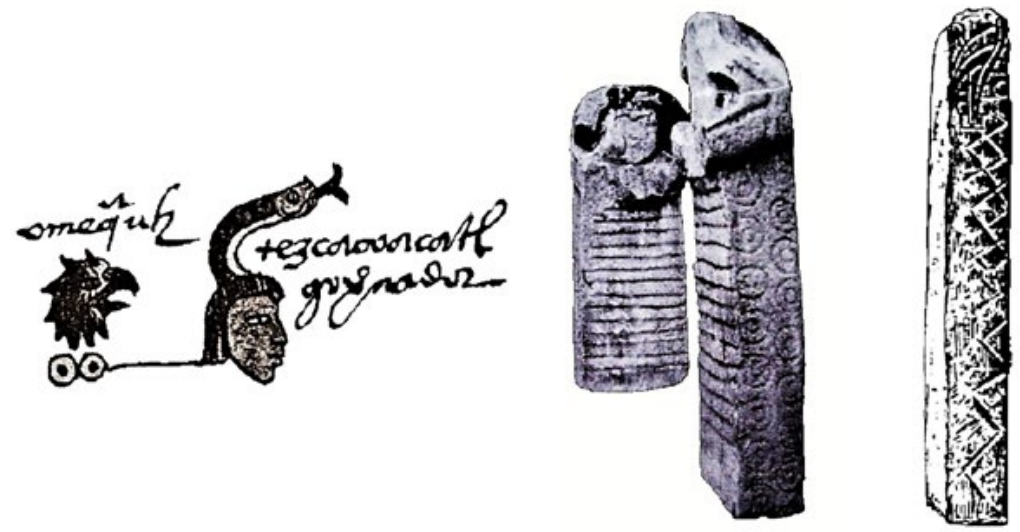

Fuente: Códice Mendoza (en Galindo y Villa, 1979:18r), Ochoa (2005:555) y Seler (1908)

Hacia 1487, la tensión hacia las provincias de la Huaxteca meridional se acentuó tras la repentina extracción de fuerzas bélicas tetzapotecas, las cuales fueron esclavizadas y utilizadas para la erección de la cuarta etapa constructiva del Templo Mayor, donde fueron sacrificadas (Márquez, 2017:15-16). Tras este evento, una importante cantidad de familias y varones fue enviada a Tetzapotitlan, con lo cual se logró detener las rebeliones constantes de dicho sitio (Márquez, 2012b:128132; 2015a:332-342; 2017:97-106). El devenir histórico resultante, producto de la estrategia referida, fue la anulación de rebeliones en los años siguientes, lo cual permitió la manutención de la explotación de la mano de obra femenina en la localidad, casi exclusivamente dedicada a la elaboración de mantas y otros productos de algodón (Márquez, 2015a:23-24). Esta producción era la que realmente importaba a los gobernantes del Altiplano, pues ayudó a implementar la estrategia de colonización previa a la eliminación de las fuerzas de producción masculinas, usualmente utilizadas para la guerra. Si no se lograba apaciguar a es-

\footnotetext{
${ }^{4}$ Una identificación previa de este tipo de representaciones sugiere que se trata de imágenes de Quetzalcóatl (Robles, 2007:235).
} 
tas fuerzas bélicas y mantenerlas bajo dominio, lo único que quedaba por hacer era exterminarlas y fue precisamente lo que se hizo, pues su existencia ocasionó altos costos en el uso de fuerzas bélicas para el logro de nuevas conquistas. Esta tesis tiene sustento en los datos en torno a las sumas de mantas tributadas por las provincias de Atlan y Tetzapotitlan a la Triple Alianza, evidentemente superiores en cantidad en relación con las procedentes de otros pueblos relevantes de la región. En promedio, cada una de ellas generaba 550 mantas, en tanto otras, como lo son Tuxpan y Tzicoac, presentaban 400 y 460 respectivamente, lo cual permite explicar por qué el Altiplano se mantenía tan empeñado en la consolidación del dominio de Tetzapotitlan. Esto permitiría, a su vez, controlar a las provincias cercanas (Márquez, 2012b: 20; 2014: 64; 2015a: 23; 2017). Así, los esfuerzos de la Triple Alianza se concentraron en el dominio de tetzapotecas, por estrategia, al encontrarse su poblado en pleno camino hacia las tierras costeras, donde podían obtenerse otro tipo de riquezas.

Así pues, la consolidación del dominio de Tetzapotitlan estuvo dada por la ocupación territorial de la Triple Alianza en la localidad, lo que permitió no solo la sujeción ideológica política y religiosa de facto, sino el desarrollo de nuevos discursos culturales por completo, los cuales debieron ocasionar el desplazamiento lingüístico del tének (Márquez, 2017). Por lo tanto, las generaciones que crecieron a partir de este nuevo régimen se mantuvieron permeadas ideológicamente desde su infancia más temprana, y modificaron o hicieron desaparecer paulatinamente otros rasgos culturales de la población local, como el sistema de creencias y demás costumbres (Márquez, 2015: 332-355; 2017: 84-136; 2020).

\section{El abandono de Tetzapotitlan en la época colonial}

A pesar de la fama ganada de Tetzapotitlan como productor de mantas de algodón desde la época prehispánica, la provincia cuenta con un vacío histórico, consecuencia del despoblamiento en la época colonial ocasionado por un hipotético exceso en las presiones tributarias. Esto, aunado a factores que afectaron a toda la región, como pestes, guerras, esclavización y malos tratos por parte de colonizadores españoles (Pérez, 2001:22, 28, 36-37). Respecto a este fenómeno, Melgarejo esclarece el panorama tributario de Tetzapotitlan durante el siglo XVI, desde poco antes de 1546 y hasta 1556, a partir de lo cual se pueden hacer algunas inferencias acerca de lo sucedido en la provincia (Melgarejo, 1970:61-63). 
Según la información presentada por Melgarejo, Tetzapotitlan es un pueblo del «corregimiento de Metateyuca», perteneciente a la «Guasteca» y que se ubica camino de Pánuco. Para antes de 1546, esta población debía entregar -entre otros tributos- 500 mantas cada 80 días; es decir, una cantidad ligeramente menor a la pagada en la época prehispánica. No obstante, la respuesta de la población no fue la esperada y, en contraposición, la solicitud en el pago de encomienda disminuyó. Para enero de 1546 se solicitaron 300 mantas y para abril de ese mismo año solamente 100, aunque tampoco hubo acuerdo. En noviembre de 1546, solo se solicitaron 100 mantas, ningún otro tipo de productos. Esta situación se mantuvo hasta 1549 y se alargó hasta 1553. El 15 de agosto de 1557, Diego Ramírez incrementó la cantidad a 360, aun cuando en 1553 se había dispuesto que la cantidad fijada permanecería por 10 años. Hacia 1566, la cantidad solicitada disminuyó drásticamente hasta quedar en 29 mantas (Melgarejo, 1970:61-63).

Como se observa, a principios de la época colonial Tetzapotitlan mantuvo su enorme productividad en relación con la elaboración de mantas, que fue constante hasta 1546. Este año la población nativa inició el abandono de la localidad, tanto por las presiones tributarias como por otros factores ya mencionados. No obstante -y pese al abandono de la localidad durante tres siglos- se ha reconocido a Tetzapotitlan como el sitio con mayor productividad algodonera en la región y aun en toda la costa del Golfo, actividad económica que le fue reconocida incluso después del yugo mexica.

Para 1566, la cantidad a tributar por parte de Tetzapotitlan había disminuido hasta casi veinte veces menos, lo cual muestra la problemática social implícita. En solamente veinte años, la población, reacia al nuevo sistema tributario, fue despoblando esta región hasta que la dejó casi en completo abandono. Pasaron trescientos años para que una población decidiera aprovechar nuevamente estas tierras, las cuales -según los datos existentes a principios del siglo XX (Seler, 1908:414)- más que matorrales y pastizales, se habían transformado en pequeños bosques.

\section{¿Tetzapotitlan o Teayo?}

Como se ha notado, la glífica de la escultura y de los documentos pictográficos, además de la información de fuentes escritas del siglo XVI, apuntan a denominar a esta provincia como Tetzapotitlan o Tetzapolco, sin que haya referencia a algún lugar denominado Teayo o Teayoc, nombre de la localidad ubicada 
apenas unos kilómetros hacia el oeste de la cabecera municipal de Castillo de Teayo (véase Figura 4). Según Melgarejo (1970: 31), este nombre lo habría tomado Tzapotitlan [sic] tras el abandono completo de la localidad. Esta inferencia no sería cuestionable si se considera la sola mención del dato, pero produce incomodidades cuando se hace evidente que en Los Lienzos de Tuxpan el topónimo de Tetzapotitlan permanece en su lugar (véase Figura 2); es decir, debe existir otro sitio o región para el cual se aplique la voz Teayo, diferente de Tetzapotitlan. Por su parte, Melgarejo (1970) precisa que se trata de «la tortuga de piedra», aun cuando no fundamenta su propuesta sobre un topónimo que, cabe decir, no se encuentra nada cerca al de Tetzapotitlan en estos documentos, como debería suceder al considerarse su posición geográfica actual (véase Figura 4). A esto, cabe decir que el actual poblado de Teayo sigue la traza del antiguo camino de Metlaltoyuca a Tetzapotitlan ubicándose a $5 \mathrm{~km}$ hacia el oeste, lo cual contrasta también con lo representado en Los Lienzos de Tuxpan, donde colinda con el río Pantepec, es decir, 20 kilómetros al norte del Teayo actual (véase Figura 5).

Figura 4. Posiciones geográficas de Teayo y Tetzapotitlan (Castillo de Teayo) en la actualidad. Nótese que la región es sumamente accidentada y con pocas llanuras

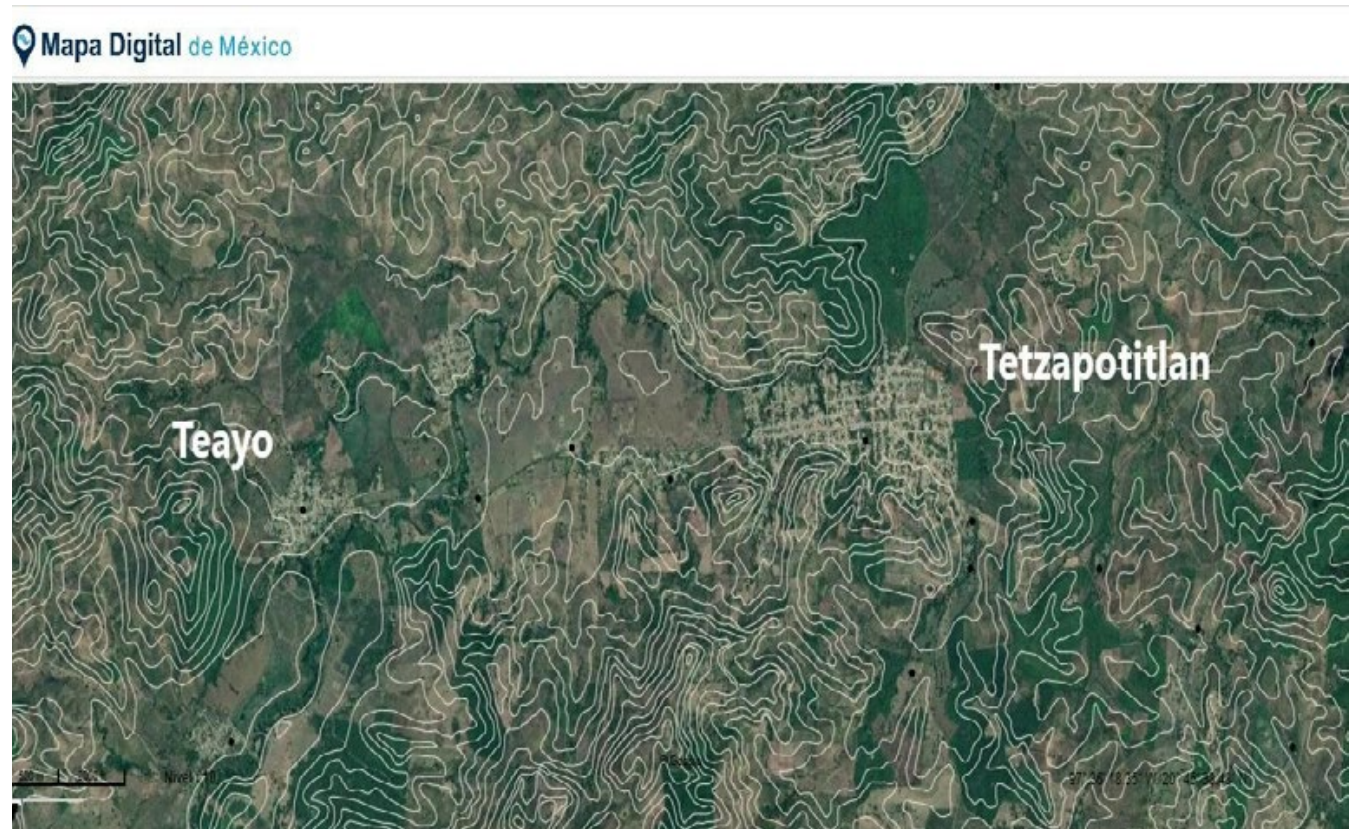

Fuente: Modificado a partir de http://gaia.inegi.org.mx/mdmb 
Figura 5. Posición geográfica de Tetzapotitlan y «Teayotlan» o «Teayoc» en el Mapa Regional Tercero de Los Lienzos de Tuxpan

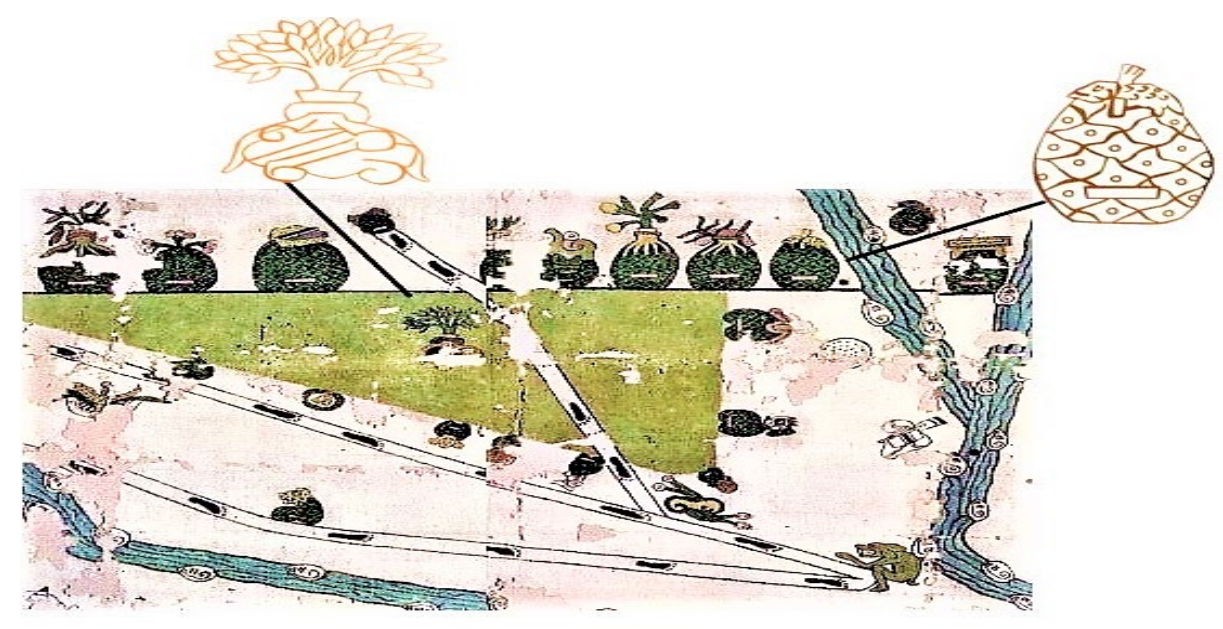

Fuente: Modificado a partir de Melgarejo (1970)

Por lo tanto, de estas observaciones se puede deducir que el topónimo denominado Teayotlan o Teayoc por Melgarejo no tiene relación con el antiguo Tetzapotitlan y menos aún con la localidad de Teayo, ubicada a $5 \mathrm{~km}$ de distancia al oeste y cuyos vestigios arqueológicos se relacionan estrechamente con los de Tetzapotitlan. De hecho, como el propio topónimo lo expresa en el Mapa Regional Tercero de Los Lienzos de Tuxpan (véase Figura 5), su imagen se compone de un reptil que puede considerarse una tortuga (ayotl) por llevar el torso con imágenes en forma de $u$, expresión característica para referirse a la tierra de cultivo en documentos pictográficos, y de la forma de un cerro precioso (tepet). Es decir, el topónimo aludido en el documento no es Teayotl, sino Ayotepetl (Ayotepec), lugar que es por demás señalado en otro de los trabajos de Melgarejo como perteneciente al «Distrito de Tuxpan» en la época de dominio mexica, el cual entregaba tributo a Texcoco (Melgarejo, 1949:323-327).

Descartada la identidad toponímica del supuesto glifo de Teayotlan o Teayo en Los Lienzos de Tuxpan, es necesario señalar la inexistencia de una imagen del topónimo como tal, de acuerdo con lo registrado en la documentación pictográfica existente, pues la imagen que había recibido ese nombre corresponde al sitio de Ayotepec. Por otra parte, la situación geográfica del topónimo corrobora dicho análisis, pues no mantiene correspondencia real en el territorio referenciado. No obstante, es de notarse que hay una serie de topónimos (ocho en total) en dirección sur a norte, que atraviesan el ya referido camino 
de Metlaltoyuca a Tetzapotitlan. De ellos, el más cercano, que podría tentativamente identificarse con la actual localidad de Teayo es el de Caltepec, formado por la imagen de una casa (calli) y un cerro (tepetl).

Ante la ausencia concreta del topónimo Teayo para la época prehispánica -como ya se mencionó- es probable que esta palabra tenga un origen y utilidad diferentes. Para explicarlo pensemos, por ejemplo, en las denominaciones que recibieron ciertas regiones en tiempos remotos, las cuales sirvieron para resaltar aspectos regionales y aun cualidades, y no tanto para reconocer o delimitar un determinado espacio geográfico. Esto aplica para conceptos lejanos como el Chicomóztoc, el Tollan o el Tlillan Tlapallan, y más localmente con el Tonacatlalpan y el Xochitlalpan, lugares de bastimentos y de flores, formas de referencia usuales a la provincia de «Cuextlan» en diversas fuentes documentales del siglo XVI (Sahagún, [1569] 2006:589-590). En este sentido, a Tetzapotitlan se le podrían también aplicar dichas acepciones si se considera que, en una de las tantas sequías ocurridas en el Altiplano, como la de 1505, los mexicas mandaron traer bastimentos de esta localidad (véase Figura 6). De hecho, este acarreo de víveres ayuda a comprender también la importancia que reviste el sitio para el gobierno de la Triple Alianza (Márquez, 2017:15).

Figura 6. Aprovisionamiento de víveres traídos desde la provincia de Tetzapotitlan en 1505, la cual estaba ocupada territorialmente

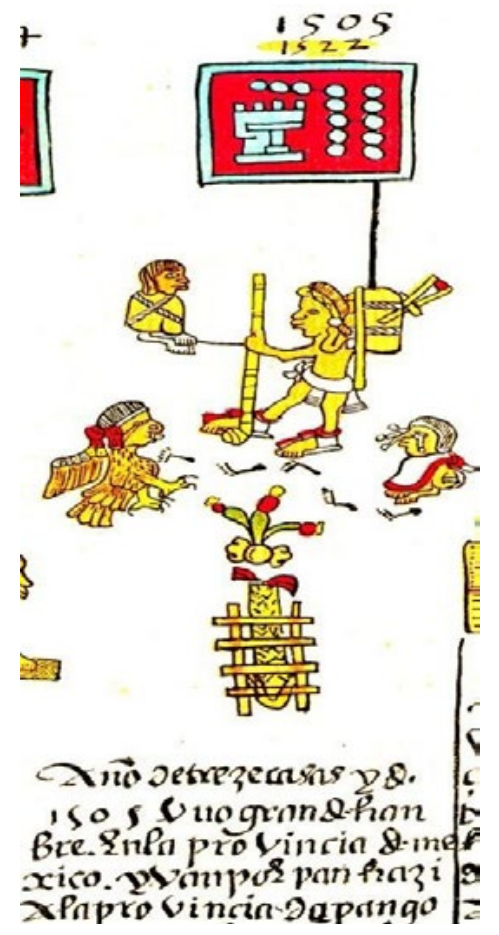

Fuente: Tomado de Códice Telleriano Remensis (Quiñones, 1995:folio 41v) 
Resulta curioso comentar, además, que el territorio al cual hace referencia Sahagún como Tonacatlalpan y Xochitlalpan se identifica por ser en extremo caluroso, con frutos que además no se dan en el Altiplano, como el quequéxquic (cosa picante) y el algodón. Al respecto, es necesario mencionar que las únicas provincias que tributaban quequéxquic (chile seco) eran Tuxpan y otros seis pueblos, Tzicoac y otros cuatro pueblos, y Oxitipan (Códice Mendoza, en Galindo y Villa, 1979: 52r,54r,55r). Sirva este ejemplo para demostrar que la denominación Cuextlan abarca una extensión territorial cualitativamente distinta a la esperada desde un punto de vista occidental, sin un espacio o región delimitados geográficamente, o en su caso, con límites difusos. Esto implica, a su vez, que una misma región puede tener varias denominaciones, premisa fundamental en esta investigación.

De manera similar al caso de Cuextlan, se encuentra el de Tetzapotitlan, o en específico, el de Teayo si se atiende primeramente a la etimología por encima de una inferencia que resulta errónea en Los Lienzos de Tuxpan, como ya se señaló. Para iniciar el cuestionamiento, es necesario considerar otros documentos históricos de la región, como el Croquis de los Terrenos de Metlaltoyuca (1883), donde se muestra un área ubicada al extremo oriental que ostenta la denominación «Tiallo» (véase Figura 7), correspondiente a un pueblo habitado en aquel entonces (Almaraz, 1866:26). Esta población, de acuerdo con Fages, correspondía a una ranchería de Tihuatlán, mencionada en otro documento de 1854 (Melgarejo, 1970:155).

Figura 7. Detalle del Croquis de los Terrenos de Metlaltoyuca, donde se indica el límite con

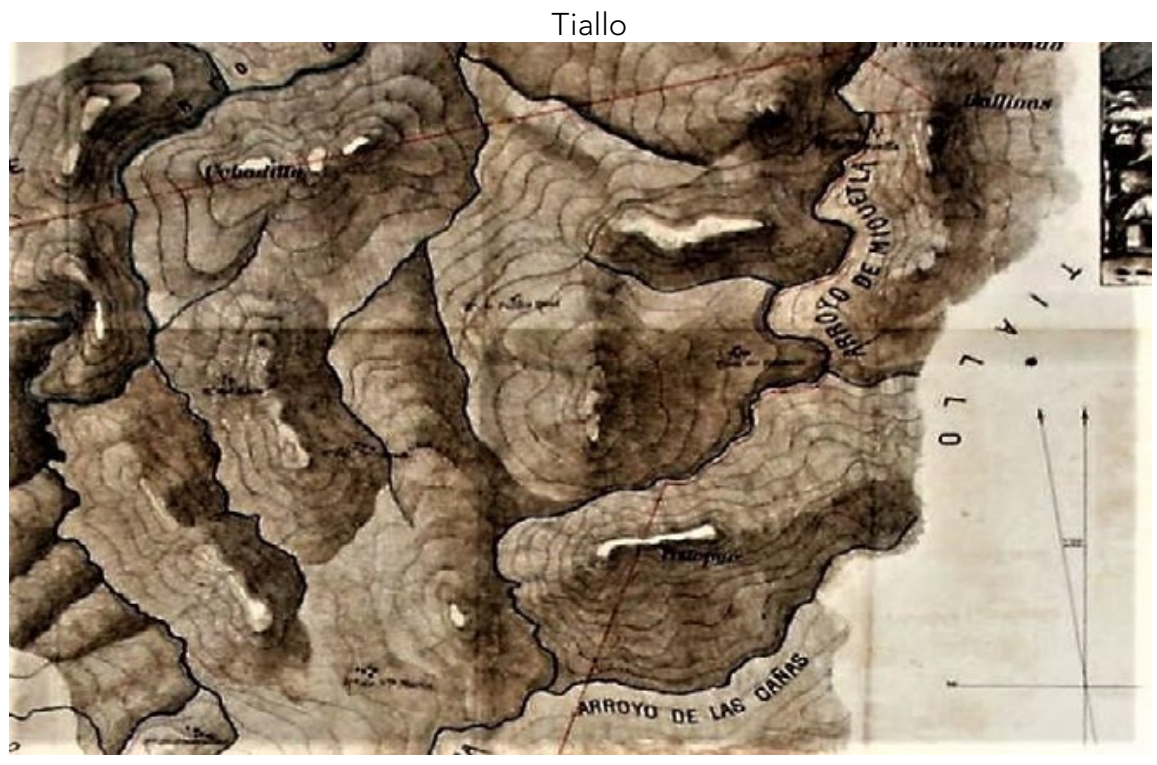

Fuente: Beltrán y Pacheco (1883) 
Si se considera que al menos tres documentos de mediados del siglo XIX se refieren a la localidad como Tiallo y no como Teayo -como se denomina actualmente- se podría pensar que la denominación Teayo pudiera ser una deformación lingüística de la palabra Tiallo, popular en las fuentes históricas de la región para el siglo XIX. Al tratar de rastrear el náhuatl clásico en la palabra Tiallo-como está documentada desde sus orígenes-, puede asumirse hipotéticamente que la voz original correspondería a Tialloc, Tiayoc o Tiayotl. ${ }^{5}$ No obstante, existen fuentes más antiguas que descartan dicha posibilidad y en las que se encuentra la expresión Theayo (1692) o Teayo (1713-1714) (Melgarejo, 1970:27-28), sin que la hipótesis mencionada tenga cabida. Aun así, queda explicar el significado de la expresión en relación con datos duros, razón por la cual todavía se descarta la tradicional acepción «en la tortuga de piedra», interpretación errónea que hizo Melgarejo (1970) al referirse al topónimo de Ayotepec como Teayo. El análisis continúa, entonces, con el objeto de precisar y comprender su acepción prehispánica, ahora desconocida por ausencia de representaciones en documentos pictográficos y de menciones en fuentes escritas del siglo XVI.

\section{Tetzapotitlan - Teayo}

Como se ha mencionado, Teayo no podría corresponderse con el topónimo de Ayotepec, razón por la cual debe descartarse su significado en cuanto «tortuga de piedra». Debe considerarse además su lejanía en relación con la actual localidad de Teayo, que en todo caso corresponde con el antiguo Caltepec. Dicho esto, debe existir otra razón por la cual esta región recibió tal denominación, diferente, a su vez, de acepciones lingüísticas relacionadas con las palabras Tialloc, Tiayoc o Tiayotl, como se había supuesto.

Por su parte, para comprender la significación y adjudicación de la expresión y ante la ausencia de una representación de escritura pictográfica alusiva concreta -como ocurre para el caso de Tetzapotitlan- es necesario considerar que la expresión pudiera tratarse de una mera referencia a una región, basada en sus características propias que pueden ser medianamente derivadas de acuerdo con datos ya referidos aquí. Por lo tanto, queda lejos la significación de «tortuga de piedra», asumida por Melgarejo en Los Lienzos de Tuxpan y precisada como Ayotepec.

\footnotetext{
${ }^{5}$ De acuerdo con Dakin, las variantes lingüísticas del náhuatl para la Huasteca tuvieron la misma ortografía que para la región del centro del país, reparando más en la uniformidad que en las variantes lingüísticas de cada región (Dakin, 2010: 220-221). Esto explica la variabilidad lingüística en la escritura de la palabra Tiallo, como viene a ser el caso.
} 
De este modo, es necesario ir más allá de las representaciones mismas, carentes, de momento, para derivar significaciones, como ocurre en el caso de lugares míticos ya referidos también. Así, se requiere aclarar que muchos de los códigos usualmente interpretados como «estéticos» desde la mirada occidental son, en muchos casos, códigos lógicos en el pensamiento indígena, pues su escritura está basada en la imagen (Márquez, 2012b:80-85). Por lo tanto, para descifrar la toponimia se hace necesario considerar otras variables en los estudios y no solamente aquellas que se encuentran emanadas del imaginario social y/o en documentos escritos. Por eso, en este estudio se realiza un esbozo histórico arqueológico de lo que fue Tetzapotitlan, Castillo de Teayo, en la época prehispánica.

En este sentido, es necesario conocer las características tanto geográficas como climáticas y diversidad en cuanto a flora y fauna propias de una región, especialmente aquellas referentes a actividades culturales que se encuentran en estrecha relación con el pensamiento humano. Toda información que permita conocer, de antemano, aspectos que hacen resaltar a unas regiones por encima de otras -ya sea por la presencia de recursos, materiales, actividades productivas o riquezas naturales- es fundamental.

Debido a estas razones, este artículo se encamina a atender el origen del término Teayo con referencia a una región y no tanto a un sitio en concreto (véase Figura 7), lo cual significa que los aspectos regionales, y, por tanto, relacionados con Tetzapotitlan, son medulares para este texto.

Tetzapotitlan destacó por una producción algodonera vasta, tan superior a la de otras regiones que generó sumo interés en la Triple Alianza por consolidar su dominio y manutención del tributo durante casi medio siglo, durante el cual hubo gran cantidad de conflictos para someter a la provincia. Ahora bien, toda esta producción algodonera debía forzosamente tener como antecedente una distribución hacia otras poblaciones para poder establecer intercambios por otros productos no generados en Tetzapotitlan. Las únicas vías posibles para el intercambio regional eran hacia Miahuapan, yendo hacia la costa, o bien con Metlaltoyuca, hacia la sierra. No obstante, aquí queda explicar cuál era la función del sitio de Caltepec, que, como se ha precisado, correspondería a la actual localidad de Teayo, de acuerdo con la información plasmada en Los Lienzos de Tuxpan y conforme a las evidencias arqueológicas propias de la región, como lo son las documentadas en el Cerro del Chale y el sitio arqueológico de El Pital, ubicados a 3 km al oeste y 1 km al sur, respectivamente (Márquez, 2015a:397-398). 
Asimismo, es necesario explicar por qué la región correspondiente a Tetzapotitlan, incluyendo los sitios arqueológicos de Caltepec y El Pital, eran denominados Teayo en su conjunto. Cabe decir, además, que Caltepec se ubicaría geográficamente en la actual localidad de Teayo, donde su posición estratégica habría permitido el establecimiento de vías comerciales hacia las tres poblaciones del sur y las cuatro del norte que se aprecian en Los Lienzos de Tuxpan. Al encontrarse en el cruce de cuatro caminos, pudo ser un sitio idóneo para la realización de un tianguis en la época prehispánica que permitiera el intercambio de mercancías producidas en cada sitio. Esto permite explicar también por qué tras lograr el control de Tetzapotitlan, Caltepec desapareció del mapa, pues las mercancías principales, consistentes en productos manufacturados de algodón, valiosamente preciados en el Altiplano, ya no se detenían para ser intercambiadas con pueblos al norte y sur de estos caminos, sino que eran llevadas directamente hacia México Tenochtitlan. De hecho, las mantas de algodón de la zona eran tan preciadas que Sahagún se refiere a ellas asegurando que los nativos «andan bien vestidos, y sus ropas y sus mantas muy pulidas y curiosas, con lindas labores, porque en su tierra hacen las mantas que llaman centzontilmatli, centzonquachtli, que quiere decir, mantas de mil colores» (Sahagún, [1569] 2006:590).

A su vez, tal situación ayuda a explicar por qué los mexicas decidieron colonizar Tetzapotitlan y no Caltepec u otras poblaciones cercanas: si se procediera así, los tetzapotecas continuarían generando guerras para romper la relación política de dominio, esto con mayores costos para la Triple Alianza en cuanto a nuevas intervenciones militares. No obstante, al establecerse en Tetzapotitlan y controlarlo localmente, se impidieron nuevas rebeliones, al tiempo que ahorcaron las relaciones comerciales de esta provincia con las ya referidas hacia el sur y norte, razón por la cual Caltepec desapareció y está ausente tanto en fuentes históricas como pictográficas del siglo XVI y posteriores.

En el Gran Diccionario Náhuatl, se puede notar que la expresión Teayo no tiene cabida, siendo las acepciones más aproximadas las de Teaio y Teayotl. Esta última, según se indica, significaría «Madre», o bien, «matriz», haciendo referencia a la anatomía humana (GDN, UNAM, 2020). De ser así, Teayo, hipotéticamente, haría referencia a un lugar donde habitan las madres, o bien, una región mítica de origen, al hacer referencia explícita de la matriz. Aquí inicia lo verdaderamente interesante en relación con el término, sobre lo cual se pueden arrojar diversidad de hipótesis que no se contraponen entre sí en su totalidad. 
En primer término, debe rescatarse la información concerniente a la alta productividad algodonera tetzapoteca. Dicha actividad era realizada por mujeres que debieron emparentar con varones mexicas tras la extracción de población masculina de la localidad para ser llevada a México Tenochtitlan y sacrificada en 1487, como estrategia de dominio y prevención de nuevas rebeliones. Por lo tanto, es razonable que la mano de obra femenina fuera fundamental para contribuir al sistema tributario de la Triple Alianza, y que de ahí derive la expresión Teayo para referirse a este lugar repleto de féminas al estar despojado de su población varonil.

Por otro lado, debe considerarse que la productividad algodonera estaba regida por la diosa tének Teem (la mal llamada Tlazoltéotl entre los mexicas), de la cual existen algunas expresiones escultóricas en Tetzapotitlan (véase Figura 8) (Márquez, 2015a:188-191). ${ }^{6}$

Figura 8. Representaciones de la diosa tének Teem
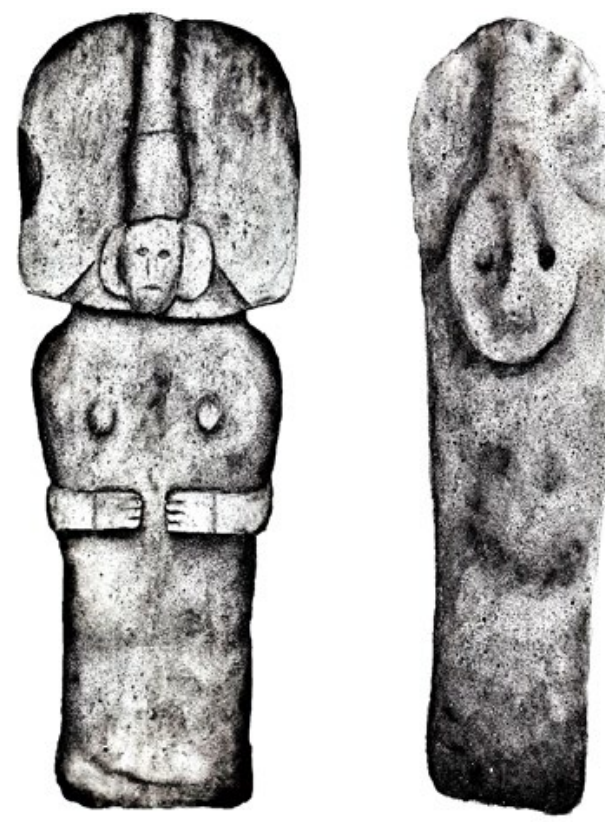

Fuente: Museo de Sitio de Castillo de Teayo y Museo de Córdoba. Dibujos de Syria Cardiel Zalapa a partir de Márquez (2009)

\footnotetext{
${ }^{6}$ Resulta altamente probable que tras la ocupación territorial de la Triple Alianza muchas de sus representaciones fueran destruidas, manteniéndose su culto cotidiano a partir de la manufactura de figurillas con sus atributos (Márquez, 2015a, 2017).
} 
Por si fuera poco, investigaciones en torno al área han demostrado un intensificado culto a númenes de los mantenimientos que, tras la instauración de la población mexica en la localidad, se intensificó con la presencia de la diosa Chicomecóatl, contraparte de Tláloc en el panteón mexica (Márquez, 2009, 2012b, 2015a, 2017, 2020, 2021). En las festividades características de la población invasora, especialmente la de Ochpaniztli, se habrían condensado las creencias entre ambos grupos culturales, donde ocurrió una especie de unificación de la diosa Madre. Dicha situación, excepcional en Mesoamérica, habría tendido a caracterizar a esta zona, razón por la cual la denominación Teayo habría sido la más adecuada para referirse a ella, si se considera, a su vez, que las representaciones de la diosa Chicomecóatl se encuentran no solamente en Tetzapotitlan, sino también en El Pital (Márquez, 2015a:397).

La significación de la expresión Teem, deidad principal de la cultura propia de los tének y que se extendió en gran parte del actual territorio de Veracruz, Tamaulipas, Puebla, Hidalgo, San Luis Potosí y Querétaro, tiene una traducción literal en tének como Vulva Madre (Márquez, 2015a:109). Se considera a este numen femenino por excelencia como procreadora de la vida, propiciadora de la fertilidad y dadora de los mantenimientos, pues se piensa que es regidora sobre la tierra y, tentativamente, madre de Dhipak, quien, como héroe cultural entre los tének, representa al maíz. Cabe destacar que en las representaciones plásticas, estos atributos se le atribuyen a Teem a partir de la postura de las manos sobre ambos lados del vientre (Márquez, 2015a:109). La denominación Teayo, por lo tanto, haría referencia al culto intensificado de este numen en la localidad, el cual se hibridaría con el de la diosa Chicomecóatl tras la instauración de grupos mexicas en la localidad a partir de 1487.

Una situación especial -que apoya estas hipótesis en torno de la significación de Teayo- es dada, a su vez, por el hallazgo de una escultura en el cerro de La Chinola, la cual presumiblemente representa a la diosa mexica del agua Chalchiuhtlicue. En el reverso de la pieza es posible ver a cuatro personajes que podrían identificarse como tlaloques, además de que se trata de quizá el único caso de manufactura de una copia prehispánica de otra escultura, la cual fue encontrada en México Tlatelolco (véase Figura 9) (Márquez, 2012b:55-61). Esta representación haría alusión a la diosa madre por excelencia. 
Figura 9. Representaciones de «Chalchiuhtlicue», halladas en Tlatelolco y La Chinola, respectivamente
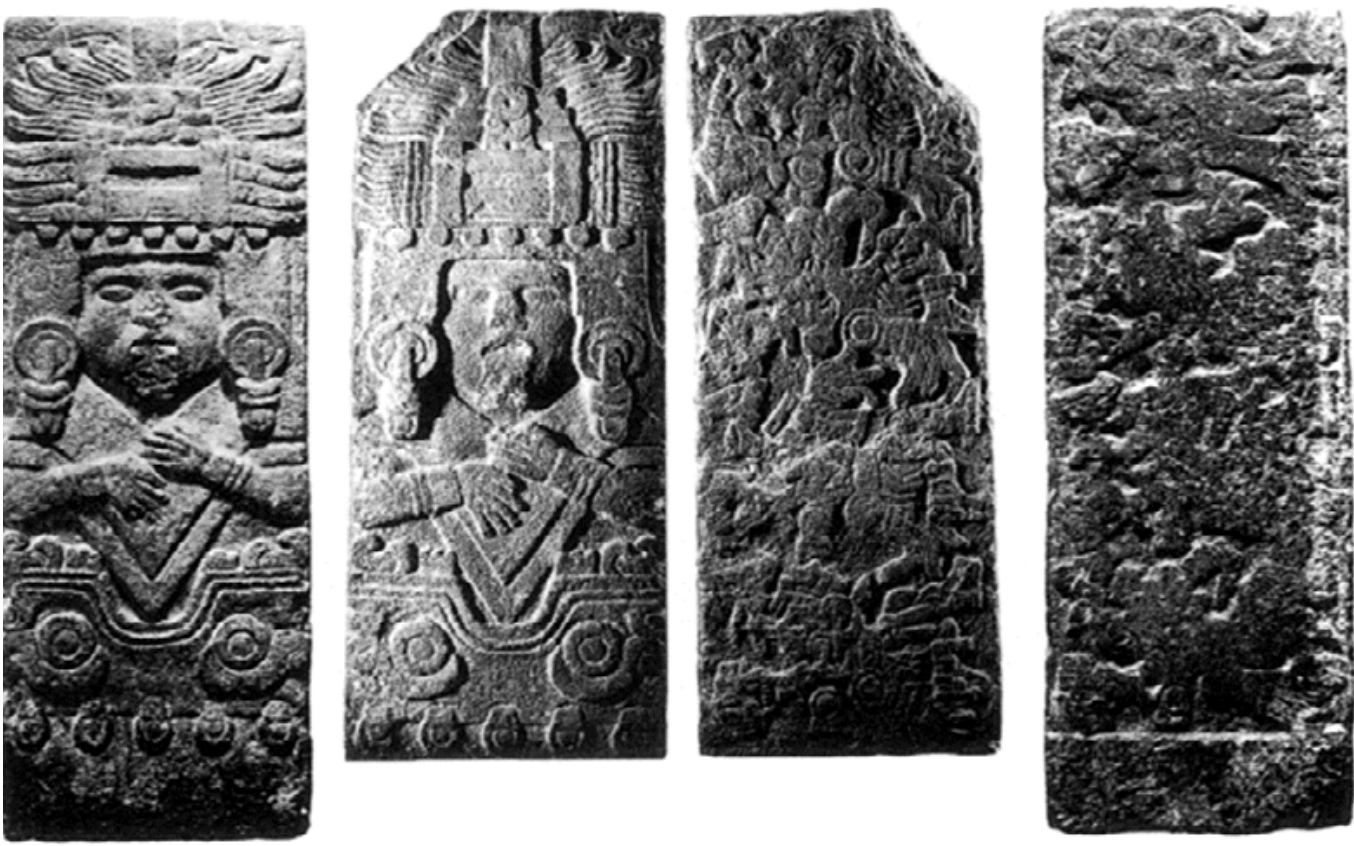

Fuente: Fuente: Maclaren (2002:155)

Por si fuera poco, es necesario comentar que actualmente el cerro de La Chinola es motivo de peregrinaciones de parte de grupos hñahñu habitantes de la localidad, quienes realizan ofrendas en el basamento prehispánico de este espacio, donde presumiblemente fue encontrada la escultura de la diosa Chalchiuhtlicue ya mencionada (Márquez, 2015a:372-381). El origen de este culto es desconocido, aunque es reportado desde principios del siglo pasado (Seler, 1908:429). Por su parte, las peregrinaciones actuales son justificadas de manera mítica por los propios hñahñu. De acuerdo con entrevistas realizadas a integrantes de estos grupos: las primeras familias llegaron porque «la reina del agua les dijo que ahí estaba su casa, pidiendo que le hicieran sus rituales en La Chinola» (K. Reyes, comunicación personal, 10/11/2020). Este planteamiento refuerza, aún más, el sentido de las hipótesis en torno a la expresión Teayo sobre la alusión a estas tierras como sitio de origen de la diosa Madre de los grupos tének, acepción cultural que fue otorgada después a la diosa Chicomecóatl de los mexicas (véase Figura 10). 
Figura 10. Monumento 6 de Tetzapotitlan, con elementos de origen tének (manos al vientre y torso desnudo) y mexica (tocado amacalli)

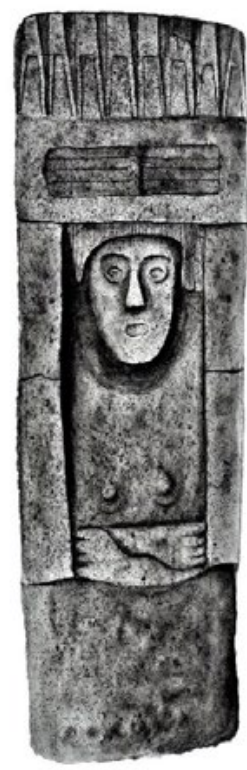

Fuente: Dibujo de Syria Cardiel Zalapa a partir de Márquez (2015:259)

Un detalle de interés que enfatiza la relevancia de Tetzapotitlan-Teayo en la Huaxteca meridional es, además, su posición geográfica. Como se nota en la Figura 4, estos pueblos se encuentran asentados en pequeñas Ilanuras alargadas, rodeados de elevaciones que restringen la comunicación con otras poblaciones, tanto de la costa como de las tierras altas. Por lo tanto, cualquier interacción comercial entre tierras altas y la costa requería de la necesaria mediación de Tetzapotitlan, con la fuerte posibilidad de que uno de los tianguis más importantes de la región fuera establecido cerca de esta zona. Por otro lado, el sometimiento de la localidad permitiría a la Triple Alianza mediar sus relaciones comerciales; de ahí se explica el esfuerzo histórico por consolidar el dominio territorial del sitio. A su vez, no es casualidad que los grupos colonizadores hayan ocupado de manera estratégica un área, que he llamado «Barrio Mexica», en el estrecho oeste y suroeste de Tetzapotitlan, desde donde podían controlar las entradas y salidas de comerciantes de la región (véase Figura 11). Cabe mencionar que esta zona corresponde actualmente al Barrio de la Cruz y Cerro de la Cruz, donde diversas evidencias demuestran la existencia de cultos mexicas no solamente agrícolas, sino discursivos en torno a la manera de atemorizar mediante el sacrificio humano (Márquez, 2009, 2015a, 2015b, 2017, 2020). 
Figura 11. Áreas de Tetzapotitlan correspondientes con el barrio mexica

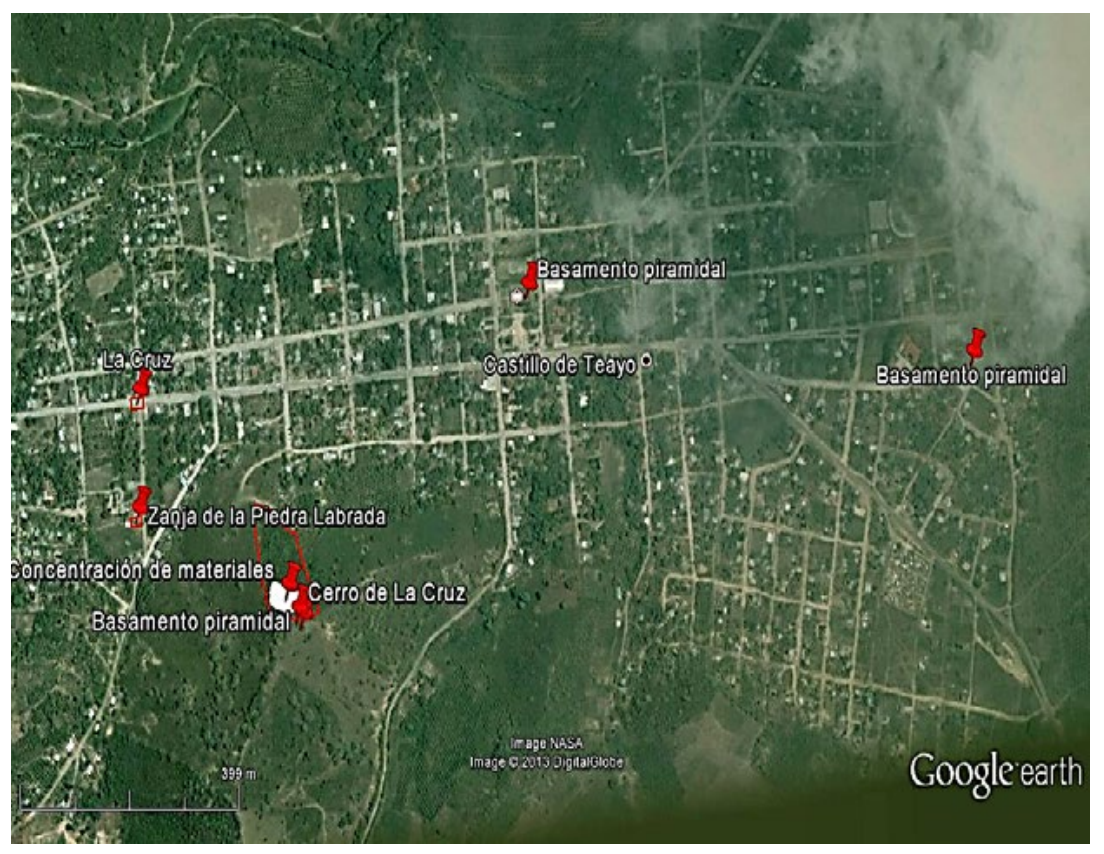

Fuente: Márquez (2015a:388)

\section{Consideraciones finales}

Este trabajo ha permitido determinar el significado del término Teayo, cuya toponimia es inexistente tanto en documentos pictográficos como en registros coloniales del siglo XVI. A su vez, por medio del análisis es posible descartar que la región aludida se relacione con el topónimo erróneamente identificado como Teayo en Los Lienzos de Tuxpan, y que corresponde a Ayotepec, sitio perteneciente a la provincia de Tuxpan, como Melgarejo comenta en otra de sus obras. Por el contrario, y con base en la comparativa con otros casos, se ha establecido que la denominación Teayo aplicada para la región de Tetzapotitlan se deriva de características diferentes a sus condiciones geográficas, puesto que más bien obedece a particularidades culturales relacionadas con la ideología política y religiosa.

El significado de Teayo como referente al «lugar de las madres» O «lugar de la Diosa Madre» sin duda se encuentra apoyado por todas las evidencias presentadas, que van desde su traducción literal hasta las históricas y arqueológicas. 
También desde la Lingüística, por traducirse como «madre» o «matriz» y resaltar el aspecto de procreación humana; etnohistóricamente, al aludir a la población femenina tetzapoteca que habría quedado a merced de la población varonil invasora de la Triple Alianza a partir de 1487; desde la Arqueología, por existir evidencia de cultos intensificados tanto a la Teem tének como a la Chicomecóatl mexica en cuanto deidades relacionadas con la producción algodonera y los mantenimientos, y etnográficamente, por ser el lugar donde grupos hñahñu indican haber llegado por razón de «la reina del agua», quien les pidió que le hicieran culto en el Cerro de la Chinola, donde fue encontrada hace más de 100 años la representación de Chalchiuhtlicue, que además es copia prehispánica fiel de otra hallada en México Tlatelolco.

\section{Agradecimientos}

El presente trabajo fue logrado gracias al financiamiento del Proyecto «La Asimilación de Discursos Mítico-Rituales Mexicas en Tetzapotitlan (Castillo de Teayo)», el cual fue obtenido a través de la convocatoria 2020 «Apoyo a la Incorporación de Nuevos Profesores de Tiempo Completo (NPTC)» emitida por el Programa para el Desarrollo Profesional Docente, para el Tipo Superior (PRODEP), perteneciente a la Secretaría de Educación Pública (SEP). El antecedente directo de este trabajo, a su vez, son las visitas de campo realizadas a la localidad desde el invierno de 2013, durante las cuales se recibió colaboración valiosa de los señores Fortino Reyes Cuevas y Beatriz Díaz Hernández, quienes me apoyaron entonces con hospedaje, alimentos y traslados. A su vez, quedo especialmente en deuda, desde entonces, con Karina de la Paz Reyes Díaz y Francisco Wilka Vázquez Suárez, quienes además se aventuraron conmigo al recorrido de algunos sitios, así como a Gilberto Díaz Hernández, conocedor a profundidad de la zona y sus alrededores. Mi agradecimiento se extiende hacia Víctor Manuel Zúñiga Vargas, encargado del Museo de Sitio de Castillo de Teayo, quien se ha mostrado siempre dispuesto a apoyarme en mis investigaciones. Sin duda alguna, debo mencionar a Luis Marcelino Martínez Francisco, gracias a quien logré documentar importante información relacionada con el culto de los hñahñu en el cerro La Chinola, y a Gilberto Cifuentes Martínez. También a Osvaldo Vázquez Díaz, gracias a quien pude conocer materiales propios de la antigua provincia tetzapoteca. Sirva este trabajo como un homenaje más a esta bella región y a su gente, que siempre me ha recibido con los brazos abiertos. 


\section{Bibliografía citada}

Almaraz, Ramón, A. (1866). Memoria acerca de los Terrenos de Metlaltoyuca. México: Imprenta Imperial. Disponible en: http://data.cervantesvirtual.com/ manifestation/267274

Alva Ixtlilxóchitl, Fernando de. (1984). Obras Históricas. Serie de Historiadores y Cronistas de Indias 4. México: Instituto de Investigaciones HistóricasUniversidad Nacional Autónoma de México, 4 a ed.

Beltrán, Francisco P. y Carlos Pacheco. (1883). Croquis de los Terrenos de Metlaltoyuca. México: Compañía Colonizadora de la Mesa de Coroneles y Metlaltoyuca en el Estado de Puebla.

Dakin, Karen. (2010). Linguistic Evidence for Historical Contacts between Nahuas and Northern Lowland Mayan Speakers. En G. Vail y C. Hernández (eds.), Astronomers, Scribes and Priests. Intellectual Interchange between the Northern Maya Lowlands and Higland Mexico in the Late Postclassic Period, (pp. 217-240). Washington D. C: Dumbarton Oaks. Disponible en: https://www.academia.edu/3093710/Linguistic_evidence_for_historical_ contact_between_Nahuas_and_northern_Lowland_Mayan_speakers

Durán, Diego de. (1975). Historia de las Indias de la Nueva España e Islas de la Tierra Firme, tomo I. México: Consejo Nacional para la Cultura y las Artes.

Easby Jr., Dudley T. (1962). A Man of the People. The Metropolitan Museum of Art Bulletin, 21(4), pp. 133-140. Disponible en:

https://www.jstor.org/stable/3257936?refreqid=excelsior\%3A58bd50a862d45242acb59a6a2414fe11\&seq=1\#metadata_info_tab_contents

Galindo y Villa, Jesús. (1979). Códice Mendoza. México: Editorial Cosmos.

García Payón, José. (1976a). Arqueología de la Huasteca. Consideraciones generales. En Román Piña Chán (coord.), Los Pueblos y Señoríos Teocráticos. El Período de las Sociedades Urbanas, (pp. 59-123). México: Instituto Nacional de Antropología e Historia.

García Payón, José. (1976b). La Huasteca. En Román Piña Chán (coord.), Los Señoríos y Estados Militaristas, (pp. 243-290). México: INAH.

García Payón, José. (1965). Descripción del Pueblo de Gueytlalpan (Zacatlan, Juxupango, Matlaltan y Chila, Papantla) 30 de mayo de 1581 de Juan de Carrión Alcalde Mayor. Xalapa: Cuadernos de la Facultad de Filosofía, Letras y Ciencias de la Universidad Veracruzana. 
García Payón, José. (1959). Informe de los Trabajos Desarrollados en la Zona Arqueológica de Castillo de Teayo, Ver., Durante la Temporada del Año de 1959, Tomo CXXXII. Estado de Veracruz: Archivo Técnico del INAH.

García Payón, José. (1950). Castillo de Teayo. Noticias sobre su Arqueología. UNI-VER. Órgano de la Universidad Veracruzana, tomo II. (16), pp. 155-164. Xalapa, Veracruz: Universidad Veracruzana.

García Payón, José. (1944). Impresiones de mi Primera Visita a la Zona Arqueológica de Castillo de Teayo, Ver., tomo CXVIII (Vol. I 1922-1948, 879.-5). Veracruz: Archivo Técnico del INAH.

Graulich, Michel y Lorenzo Ochoa. (2003). La Lápida de la Calzada, ¿Una Representación de Conquista en el Sur de la Huaxteca? Anales de Antropología, 37 (1), pp. 93-116. Disponible en: http://www.revistas.unam. mx/index.php/antropologia/article/view/16736/pdf_152

Gran Diccionario Náhuatl, UNAM. (2020). Gran Diccionario Náhuatl. Disponible en:https://gdn.iib.unam. $m x /$ termino/search?queryCreiterio=teayo\&queryPartePalabra=inicio\&queryBuscarEn=nahuat/GrafiaNormalizada\&queryLimiteRegistros $=50$ (consulta: 10/11/2020).

Hernández Andón, Elia. R. (2009). Manuscrito 040 Historia Mexicana 1194-1221. En Luz María Mohar Betancourt (coord.), Amoxcalli. La Casa de los Libros. México: CIESAS.

Instituto Nacional de Estadística y Geografía. (2020). Mapa digital. Disponible en: http://gaia.inegi.org.mx/mdm-client/?v=bGFOOjlwLjczMTYOLGxvbjotOTcuNjY2MTksejo3LGw6YzExMXN/cnZpY2lvc3xOYzExMXN/cnZpY2lvcw== (consulta: 07/12/2020)

Maclaren Walsh, Jane. (2002).The Smithsonian Water Goddess: An Aztec Sculpture Rediscovered. Anthropology and Aesthetics, (42), pp.142-158. Disponible en: https://www.researchgate.net/publication/294313153_The_ Smithsonian_Water_Goddess_An_Aztec_Sculpture_Rediscovered

Márquez Lorenzo, Emmanuel. (2021). Relaciones Políticas entre Grupos Nahuas y Tének en el Epiclásico y Posclásico de Mesoamérica. Revista Española de Antropología Americana, en prensa.

Márquez Lorenzo, Emmanuel. (2020). Estética y Poder en Castillo de Teayo: Las Representaciones Mexicas y sus Implicaciones Sociales. En N. Schulze, M. N. Caretta, y L. Beckett (eds.), Expresiones Materiales del Poder en el Contexto Arqueológico del México Prehispánico, (pp.133-159). México: Universidad Autónoma de San Luis Potosí/Bornholms Museum/ El Colegio de Michoacán 
A. C. Disponible en: http://sociales.uas/p.mx/Documents/Publicaciones/ Libros/ExpresionesMateriales.pdf

Márquez Lorenzo, Emmanuel. (2019). Tetzapotitlan: The Toponym of the Preterite Society of Castillo de Teayo, Journal of Historical Archaeology and Anthropological Sciences, 4(1), pp. 26-31. Disponible en: https://medcraveonline.com/JHAAS/JHAAS-04-00176.pdf

Márquez Lorenzo, Emmanuel. (2017). El Dominio Mexica de Tetzapotitlan. El Ejercicio del Poder y sus Repercusiones Ideológicas. Xalapa: Edición del autor. Márquez Lorenzo, Emmanuel. (2015a). Evidencias de Imposición de Cultos Mexicas en Tetzapotitlan, México. Tesis de doctorado inédita. México: ENAH. Disponible en: https://mediateca.inah.gob.mx/repositorio/islandora/ object/tesis\%3A2542

Márquez Lorenzo, Emmanuel. (2015b). La Conformación Militarista de la Sociedad Mexica. En Martín Terrones Calvario, Joel Solís Pérez, Jorge Ramírez López y Guadalupe Salazar Vázquez (eds.), Memoria del primer Congreso Nacional de Historia Militar de México, a través de los Archivos Históricos, tomo I (pp. 157-174). México: Dirección General de Archivo e Historia de la SEDENA. Disponible en: http://www.sedena.gob.mx/pdf/1er_congreso/Tomo_I.pdf

Márquez Lorenzo, Emmanuel (2015 c). Arqueología de Castillo de Teayo. En Manuel Martínez Morales y José Velasco Toro (coords.), Viaje por la Ciencia (pp. 145149). Xalapa: Gobierno del Estado de Veracruz/Secretaría de Educación de Veracruz/Consejo Veracruzano de Investigación Científica y Desarrollo Tecnológico/Consejo Nacional de Ciencia y Tecnología. Disponible en: https://www.uv.mx/cienciauv/files/2017/03/Libro_viaje-por-la-ciencia_13.pdf Márquez Lorenzo, Emmanuel. (2014). Arqueología de Castillo de Teayo. La Ciencia y El Hombre, XXVII (1), pp. 62-65. Disponible en: https://www.uv.mx/cienciahombre/revistae/vol27num1/articulos/arqueologia-castillo-teayo.html

Márquez Lorenzo, Emmanuel. (2012a). El Análisis del Monumento 4 de Castillo de Teayo y la Correlación de Calendarios: Xiuhpohualli, Tonalpohualli, Toxiuh Molpilia y Romano. Cuicuilco, 19(53), pp. 97-135. Disponible en: http://www.scielo.org.mx/pdf/cuicui/v19n53/v19n53a5.pdf

Márquez Lorenzo, Emmanuel. (2012b). Aspectos Teóricos y Metodológicos para el Análisis de las Representaciones de Tláloc y Chicomecóatl en Tetzapotitlan (Castillo de Teayo). Tesis de maestría inédita. México: ENAH. Disponible en: https://mediateca.inah.gob.mx/repositorio/islandora/object/tesis:572 
Márquez Lorenzo, Emmanuel. (2009). La 'Piedra del Maíz' de Castillo de Teayo. La Imposición de Cultos como Estrategia de Dominación Ideológica de la Triple Alianza. Tesis de licenciatura inédita. Xalapa, México: Universidad Veracruzana. Marquina, Ignacio. (1951). Arquitectura Prehispánica. México: INAH/ Secretaría de Educación Pública.

Matos Moctezuma, Eduardo. (2015). ¿Una momia egipcia en una escultura de Metlaltoyuca, Puebla? Arqueología Mexicana, 136 (XXIII), pp. 8687. Disponible en: https://arqueologiamexicana.mx/mexico-antiguo/ una-momia-egipcia-en-una-escultura-de-metlaltoyuca-puebla

Melgarejo Vivanco, José Luis. (1970). Códices de Tierras. Los Lienzos de Tuxpan. Xalapa: Universidad Veracruzana. Disponible en: https://www.uv.mx/colecciones/melgarejovivanco/pdf/lienzosTuxpan.pdf

Melgarejo Vivanco, José Luis. (1949). Historia de Veracruz. México: Gobierno del Estado de Veracruz.

Mohar Betancourt, Luz María. (2009). Códice en Cruz. Estudio e interepretación. En Luz María Mohar Betancourt. Amoxcalli. La Casa de los Libros. México:CIESAS.

Pérez Zevallos, Juan Manuel. (2001). La Visita de Gómez Nieto a la Huasteca. 1532, 1533. México: CIESAS/El Colegio de San Luis/CEMCA/AGN.

Ochoa Salas, Lorenzo. (2005). En Balsa de Mangle y de Bejuco por la Historia de la Arqueología Huaxteca. En Ernesto Vargas Pacheco (ed.), IV Coloquio Pedro Bosch Gimpera. Veracruz, Oaxaca y Mayas II, (pp. 549-584). México: IIA-UNAM. Orellana, Rafael T. (1948). Informe de los Trabajos de Reconstrucción y Consolidación de Castillo de Teayo, Ver. (Tomo CXVIII, Vol. I 1922-1948, 880.6.- 10 páginas y 7 fotografías). Estado de Veracruz: Archivo Técnico del INAH. Quiñones, Eloise (ed.). (1995). Códice Telleriano Remensis. Austin, United States: University of Texas Press.

Robles Castellanos, José F. (2007). Culhua México. Una Revisión ArqueoEtnohistórica del Imperio de los Mexica Tenochca. México: INAH.

Sahagún, Bernardino de. (2006). Historia General de las Cosas de Nueva España. México: Porrúa, 11a. ed.

Seler, Eduard. (1908). Die Altertümer von Castillo de Teayo, Verhandlungen des XIV Internationalen Amerikanistenkongresses, Stuttgart, 1904. En Eduardo Seler, (ed.), Gesammelte Abhandlungen zur Amerikanischen Sprach- und Alterthumskunde (sic)(pp. 410-449). Berlin: Behrend \& Co. 
Solís Olguín, Felipe. (1996). Dos Ejemplos de Regionalización del Arte Mexica: la Sierra Norte de Puebla y Castillo de Teayo, Veracruz. En José Guadalupe Victoria, Elisa Vargas Lugo y María Teresa Uriarte (comp.), Regionalización en el Arte. Teoría y Praxis. Coloquio Internacional de Historia del Arte, (pp. 53-63). Sinaloa: Gobierno del Estado de Sinaloa/ Instituto de Investigaciones Estéticas-UNAM.

Solís Olguín, Felipe. (1986). La Estructura Piramidal de Castillo de Teayo. Un Edificio en Proceso Constructivo o un Peculiar Estilo Arquitectónico. Cuadernos de Arquitectura Mesoamericana, 8, pp. 72-79. Disponible en: https://drive.google.com/file/d/1nPFzpkjIF6L_3LO0_sBC8f5Y9l6fvJhf/view

Solís Olguín, Felipe. (1981). Escultura del (sic) castillo de Teayo, Veracruz, México (catálogo). México: Instituto de Investigaciones Estéticas-UNAM.

Stresser-Péan, Guy. (2008). Los nahuas del sur de la huaxteca y la antigua extensión meridional de los huaxtecos. En Guilhem Oliver (coord.), Viaje a la Huasteca con Guy Stresser-Péan, (pp. 134-136). México: FCE/ CEMCA.

Umberger, Emily. (2007). Historia del arte e Imperio Azteca: La evidencia de las esculturas. Revista Española de Antropología Americana, 37(2), pp. 165202. Disponible en: https://revistas.ucm.es/index.php/REAA/article/view/ REAA0707220165A/23111

Urquijo Torres, Pedro S. (2008). Paisaje, Territorio y Paisaje Ritual: La Huasteca Potosina. Estudio de Geografía Histórica. Tesis de maestría inédita. México: Universidad Michoacana de San Nicolás Hidalgo. Disponible en: http://bibliotecavirtual.dgb.umich.mx:8083/xmlui/bitstream/handle/DGB_ UMICH/2374/IIH-M-2008-0006.pdf?sequence=1\&isAllowed=y

\section{Cómo citar este artículo:}

Márquez Lorenzo, Emmanuel. (2021). Tetzapotitlan-Teayo. Precisiones toponímicas en la Huaxteca meridional, México. Revista Pueblos y fronteras digital, 16, e-503, pp. 1-27, doi: 10.22201/cimsur.18704115e.2021.v16.503 